\section{ELECTRON MICROSCOPY}

\section{Proceedings of the European Regional Conference on Electron Microscopy}

Delft, 1960. Edited by A. L. Houwink and B. J. Spit. Vol. 1: Pp. i-xvi + 1-608. Vol. 2: Pp. xviixxvii + 609-1075. (Delft: Nederlandse Vereniging voor Electronenmicroscopie, 1961.) 135 florins the two volumes.

$T$ is very appropriate that the 1960 Regional 1 Conference on Electron Microscopy should have been held at Delft, as was the first Conference in 1949. Delft is in a very real sense the birthplace of microscopy, and it is a fitting tribute to Antony von Leeuwenhoek, possibly the most acute of all microscopists, and a happy gesture that the covers of these two volumes should be impressed with an image of one of his microscopes. The twelve years which have elapsed since the first Conference have witnessed spectacular advances in this newer form of microscopy, both in technique and in the number of workers using the instrument. It could scarcely have been imagined, for example, that stemming from the first ultra-thin section demonstrated at Delft by Brettschneider in 1949 , the use of sectioning for electron microscopy would by 1960 have become so routine a matter as to be in regular use in a multitude of electron microscope laboratories. Indeed, what impresses the reader of these volumes the most is both the range of materials which can be examined by this means and the extremely rapid, even explosive, burst of interest developed during these few years.

The books comprise reports of 246 articles presented at the Conference, copiously illustrated by electron micrographs. They are not therefore intended to be read, in the sense that text-books are read, but rather to be used as works of reference. The first volume, containing 138 articles, deals in the main with instrumentation, including an article on specimen techniques, with crystal physics and with metallurgical and other industrial applications. The second, of 108 articles, is devoted exclusively to biology. The leading article in Volume 1 deals with electron optics, leading naturally to a discussion of developments both in electron microscopes and in methods of use. The articles on solid-state physics (including crystal growth and lattice defects) are perhaps especially notakle. In Volume 2 the cytology of muscle, skin, bone, sense organs, spermatozoids, and viruses all receive due attention. It is somewhat disappointing to see that while animal cytology is represented by a hundred articles, plant cytology accounts for only eight.

These two books together cover much of the field as explored in 1960 . Even a cursory glance through the list of contents, however, reveals the absence of some names already famous in the field of electron microscopy and some lines of research, both well established and developing, which are not represented. This is clearly a fault neither of the organizers of the Conference nor of the editors, and explanation is surely to be sought on other and more fundamental lines. One contributory fector is that conferences on electron microscopy by their very nature meet only part of the needs of electron microscopists. Few workers are specifically interested in the instrument itself or even in their own electron micrographs alone. Rather are they interested in the results of electron microscopy as illuminating their own chosen fields and as contributing to the solution of problems often already stated before the advent of this new technique and of interest also to non-microscopists. They therefore both receive and confer more benefit by discussions in conferences arranged by their own professional bodies, before audiences acquainted with and sympathetic to their problems, than by reports to those with whom the only interest in common is the instrument itself. While it is clearly satisfactory to electron microscopists that they should form societies, and hold symposia which attract large numbers of articles, and while it is clearly desirable that electron microscopists should meet from time to time, it is not self-evident that the best interests of the separate sciences are achieved in this way.

The books are beautifully produced on excellent paper and the illustrations could in most cases scarcely have been better. Bibliographies are attached to each article, and each volume carries a complete author index. Both the publishers and the editors are to be complimented on this work. It is notable, moreover, that in these days of publication delays, the books have appeared in less than one year from the date of the Conference; it is not easy to see how this herculean task has been performed and the editors are to be highly commended on it.

Anyone who wishes to acquaint himself with the situation in electron microscopy up to 1960 could do no better than to read these two volumes.

\section{R. D. Preston}

\section{FLORA OF THE ZAMBEZI BASIN}

\section{Flora Zambesiaca}

Mozambique; Federation of Rhodesia and Nyasaland; Bechuanaland Protectorate, Vol. 1, Part 2. Edited by A. W. Exell and H. Wild. Pp. vi + 337-581. (London: Crown Agents for Oversea Governments and Administrations, 1961. Published on behalf of the Governments of Portugal, The Federation of Rhodesia and Nyasaland, and the United Kingdom.) $25 s$.

HE second part of the first volume of Flora Zambesiaca has made its welcome appearance. The part completes Volume 1, for which an index and title-page are provided. It covers the flowering plants from family 21, Caryophyllacene to family 30 , Sterculiaceae arranged in the Bentham and Hooker sequence. The joint editors are Mr. A. W. Exell of the British Museum (Natural History) and Dr. H. Wild of the Federal Herbarium, Salisbury, Southern Rhodesia. This part, as in the case of the first part, is an excellent example of botanical co-operation, for it contains contributions by botanists working at the British Museum (Natural History), the Federal Herbarium, Salisbury, Southern Rhodesia, the Botanical Laboratory of the Free University, Brussels, the National Herbarium, Pretoria, and the Royal Botanic Gardens, Kew, while the Portuguese Government is represented both on the Managing Committee and the editorial board of this Flora. The Flora covers the Federation of Rhodesia and Nyasaland, Mozambique and Bechuanaland Protectorate. The part under review contains accounts of 10 families, consisting of 55 genera and 265 species. The largest family is the Malvaceae with 16 genera and 111 species in the area, while the smallest is the Theaceae with one monotypic genus, Ficalhoa, alone. The plants included range from small annual herbs with inconspicuous flowers such as Bergia (in the Elatinaceae) to large 